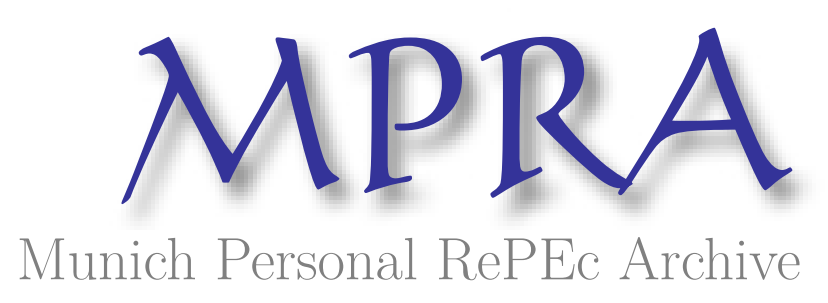

\title{
Transboundary Pollution and Absorptive Capacity
}

Ben Youssef, Slim

Ecole Supérieure de Commerce de Tunis

5 September 2009

Online at https://mpra.ub.uni-muenchen.de/17158/

MPRA Paper No. 17158, posted 07 Sep 2009 18:59 UTC 


\title{
Transboundary Pollution and Absorptive Capacity*
}

\author{
Slim Ben Youssef \\ Ecole Supérieure de Commerce de Tunis \\ Campus Universitaire, Manouba 2010 \\ Tunisia \\ slim.benyoussef@gnet.tn
}

Phone: (00 216) 97363596

September 5, 2009

\begin{abstract}
The impact of the investment in absorptive capacity on transboundary pollution is studied by considering two countries each of them regulating a firm. Firms can invest in original research and in absorptive research to lower their pollution intensity. The absorptive research enables a firm to capture part of the original research made by the other one. We show that by means of adequate emission taxes, original and absorptive R\&D subsidies, non-cooperating regulators can reach the social optimum. Interestingly, we show that the investment in absorptive research enables non-cooperating regulators to better internalize transboundary pollution. The higher is the ability parameter of absorption, the greater is the proportion of transboundary pollution internalized. Therefore, it is recommended for the international community to make the patent laws more flexible and enabling learning from the research made by others more interesting.
\end{abstract}

Keywords: Transboundary Pollution; Original Research; Absorptive Research; Internalization; Social Optimum.

JEL classification: D62; H21; C72; O32

\footnotetext{
* I would like to thank Georges Zaccour for fruitful discussions.
} 


\section{Introduction}

The ozone layer depletion and global warming are examples of damages engendered by tranfrontier pollution and are caused by the total emissions of gazes such as the carbon dioxide. Transboundary pollution is therefore a negative externality among countries which usually does not lead non-cooperating countries to the Pareto-optimality. Nevertheless, some authors showed that non-cooperating governments can reach the first best under some conditions (Hoel (1997), Zagonari (1998)). By developing a static two-country, two-good general equilibrium model, Takarada (2005) investigated the welfare effects of the transfer of pollution abatement technology when cross-border pollution exists. He derived and interpreted the conditions under which technology transfer enriches the donor and the recipient. While the tax competition literature showed that tax rates are set too low in the non-cooperative Nash equilibrium with respect to the cooperative one, Bjorvatn and Schjelderup (2002) showed that international spillovers from public goods reduce tax competition. Ben Youssef (2009) showed that R\&D spillovers and the competition of firms on the common market help non-cooperating countries to better internalize transfrontier pollution.

Our paper differs from the existing literature by the fact that we study transborder pollution using a model where firms can invest in absorptive research to capture part of the original research developed by others.

Cohen and Levinthal (1989) were the first to introduce the idea of absorptive capacity in the (process or cost reduction) R\&D literature. Contrary to the result in the seminal paper by D'Aspremont and Jacquemin $(1988,1990)$ where R\&D spillovers are assumed exogenous and cost free, Cohen and Levinthal showed that intra-industry spillovers may encourage R\&D investment. Poyago-Theotoky (1999) analyzed a simple non-tournament model of R\&D where firms engage to reduce their cost of innovation. She showed that, when spillovers of information are endogenized, non-cooperative firms never disclose any of their information, whereas they will always fully share their information when they cooperate in R\&D. Kamien and Zang (2000) modeled a firm's effective R\&D level that reflects how both its R\&D 
approach (firm specific or general) and R\&D level influence its absorptive capacity. Leahy and Neary (2007) specified a general model of the absorptive capacity process and showed that costly absorption raises the effectiveness of own R\&D and lowers the effective spillover coefficient thus weakening the case for encouraging research joint venture (RJV) even if there is complete information sharing between firms. Milliou (2009) showed that the lack of full appropriability can lead to an increase in R\&D investments. Hammerschmidt (2006) considered a two-stage game in which R\&D plays a dual role: First, it generates new knowledge and second, it develops a firm's absorptive capacity. She found that firms will invest more in R\&D to strengthen absorptive capacity when the spillover parameter is higher.

Ben Youssef and Zaccour (2009) considered a duopoly competing in quantities and where firms can invest in R\&D to control their emissions. They distinguished between effort carried out to acquire first-hand knowledge (original R\&D) and effort to develop an absorptive capacity to be able to capture part of the knowledge developed by rival. There are also free R\&D spillovers between firms. They showed that a regulator can reach the social optimal outcome by implementing a taxation and subsidy policy. The regulator subsidizes at a higher rate original R\&D effort than its absorptive capacity counterpart when the free spillovers are high, and the contrary may occur when the free spillovers are low. When the cost of original research is lower than the one of absorptive research, or when the learning parameter of the latter is low, then the socially optimal level of original research is higher than the one of absorptive capacity. The opposite result holds when the cost of absorptive capacity is lower than the one of original research and when the learning parameter is high.

We consider a three-stage game consisting of two identical regulator-firm hierarchies. Each firm produces, while polluting, one good sold on the domestic market. Firms invest in original research which directly reduces their emissions/output ratios. They also invest in absorptive research enabling a firm to benefit from the original research made by the other one. Part of the pollution of firm $i$ is exported to country $\mathrm{j}$. Since each firm constitutes a monopoly polluting the environment, it is regulated. In the first stage, each regulator non-cooperatively 
announces a tax per-unit of pollution to induce the socially optimal level of pollution and production, a subsidy per-unit of original research to induce the socially optimal level of original research, and a subsidy per-unit of absorptive research to induce the socially optimal level of absorptive capacity. In the second stage, each firm invests in $R \& D$ and in the third one they offer their production on the domestic market.

Interestingly, we show that the investment in absorptive research enables noncooperating regulators to better internalize transboundary pollution. The higher is the ability of absorption, the greater is the proportion of transboundary pollution internalized. This constitutes an important result of this paper which is due to the second stage of investment in research. Indeed, transboundary pollution has been mostly studied by static models which showed that transboundary pollution is completely not internalized by non-cooperating countries when the damage function, as in our model, is separable with respect to the pollution remaining at home and the one received from other countries (Mansouri and Ben Youssef (2000)). Nevertheless, Ben Youssef (2009) showed that R\&D spillovers and the competition of firms on the common market help non-cooperating countries to better internalize transboundary pollution.

We also prove that non-cooperating regulators can reach the social optimum by means of the three regulatory instruments defined above.

The paper is structured as follows. Section 2 presents the model, in Section 3 we characterize the socially optimal production and R\&D levels, in Section 4 we derive the socially optimal regulatory instruments, and in Section 5 we conclude. An appendix contains some proofs.

\section{The model}

We consider a symmetric model consisting of two countries and two firms. Firm $i$ located in country $i$ is a regional monopoly and produces good $i$ in quantity $q_{i}$ sold in the domestic market having the following inverse demand function $p_{i}=a-2 q_{i}, a>0$. One reason for the market structure we use is that the 
markets of the industries that engage in large investments in $R \& D$ are usually oligopolistic. Also, we suppose that markets are separated for simplicity.

The production process generates pollution and firms can invest in R\&D in order to lower their fixed emission/output ratio. We distinguish between original research, denoted by $x_{i}^{o}$, which directly reduces the emission ratio and costs $k^{o}\left(x_{i}^{\grave{a}}\right)^{2}, k^{o}>0$, and absorptive research, denoted by $x_{i}^{a}$, which enables a firm to capture part of the original research made by the other firm and costs $k^{a}\left(x_{i}^{a}\right)^{2}, k^{a}>0$. For simplicity, we suppose that there is no free R\&D spillovers between firms.

The effective R\&D level of firm $i$ is:

$$
x_{i}=x_{i}^{o}+l x_{i}^{a} x_{j}^{o}
$$

Where $l>0$ is a learning or absorptive parameter.

By normalizing the emission per-unit of production to one without innovation, the emission/output ratio of firm $i$ is:

$$
e_{i}=1-x_{i}^{o}-l x_{i}^{a} x_{j}^{o}
$$

Therefore, the pollution of firm $i$ is $E_{i}=\left(1-x_{i}^{o}-l x_{i}^{a} x_{j}^{o}\right) q_{i}$.

Since firm $i$ is a regional monopoly that pollutes the domestic environment, it is regulated. Each regulator behaves non-cooperatively and maximizes his own social welfare function by using three instruments: ${ }^{1}$ an emission-tax per-unit of pollution $t_{i}$ to induce the non-cooperative socially optimal levels of production and pollution, a subsidy per-unit of original R\&D level $r_{i}^{o}$ and a subsidy per-unit of absorptive R\&D level $r_{i}^{a}$ to induce the non-cooperative socially optimal levels of effective R\&D and emission/output ratio. Therefore, each regulator chooses the non-cooperative socially optimal per-unit emission-tax and per-unit R\&D subsidies in the first stage given the reaction of his firm which chooses its optimal levels of R\&D and production in the second and third stages, respectively. Thus, by backward

\footnotetext{
${ }^{1}$ These three instruments are necessary in this model. Indeed, even if the non-cooperative socially optimal level of pollution can be implemented by only one instrument, such as pollution permits, there is no incentive for firms to implement the socially optimal levels of production and R\&D. Thus, the non-cooperative optimal social welfare level can not be realized.
} 
calculations up to the beginning of the game, we determine the three-stage subgameperfect Nash equilibrium.

If we denote the marginal cost of production by $\theta>0$, the profit of firm $i$ is $\Pi_{i}=p_{i}\left(q_{i}\right) q_{i}-\theta q_{i}-k^{o} x_{i}^{o 2}-k^{a} x_{i}^{a 2}$, and its profit net of taxes and subsidies is $V_{i}=\Pi_{i}-t_{i} E_{i}+r_{i}^{o} x_{i}^{o}+r_{i}^{a} x_{i}^{a}$.

There are also negative externalities between countries through transborder pollution. Damages caused to country $i$ are $D_{i}=\alpha E_{i}+\gamma E_{j}$, where $\alpha>0$ is the marginal damage of the domestic pollution, and $\gamma>0$ is the marginal damage of the foreign pollution. Notice that even when $\alpha$ and $\gamma$ are different, the model still remains symmetric because these parameters are the same for the two countries. This damage function can explain a pure transfrontier pollution problem when $\alpha=d(1-c)$ and $\gamma=d c$, where $0<\mathrm{c}<1$ is the proportion of pollution of firm $j$ exported to country $i$. It can also explain an international environmental problem, when $\alpha=\gamma$, because damages in one country become a function of total pollution.

The consumer surplus in country $i$ engendered by the consumption of $q_{i}$ is $C S_{i}=\int_{0}^{q_{i}} p_{i}(u) d u-p_{i}\left(q_{i}\right) q_{i}=q_{i}^{2}$.

The social welfare of a country is equal to the consumer surplus, minus damages and subsidies, plus taxes and the net profit of the domestic firm, and is equal, after simplifications, to:

$$
S_{i}\left(q_{i}, q_{j}, x_{i}^{o}, x_{i}^{a}, x_{j}^{o}, x_{j}^{a}\right)=C S_{i}-D_{i}+\Pi_{i}
$$

Notice that taxes and subsidies do not appear in the social welfare function because the tax diminished from the firm's profit is added to the consumer welfare, and the subsidies added to the firm's profit are diminished from the consumer welfare.

\section{The non-cooperative socially optimal production and R\&D levels}

Each regulator maximizes, respectively in the third and second stages, his social welfare with respect to the production quantity and the R\&D levels.

Expression (1) can be written as: 


$$
S_{i}=q_{i}^{2}-\alpha\left(1-x_{i}^{o}-l x_{i}^{a} x_{j}^{o}\right) q_{i}-\gamma\left(1-x_{j}^{o}-l x_{j}^{a} x_{i}^{o}\right) q_{j}+\left(a-2 q_{i}\right) q_{i}-\theta q_{i}-k^{o} x_{i}^{o 2}-k^{a} x_{i}^{a 2}
$$

Expression (2) shows that when regulator $i$ chooses his optimal production level in the third stage, then transboundary pollution is completely not internalized since the parameter $\gamma$ disappears. This is general for static models with a damage function linear with respect to the total pollution, or a separable one with respect to the pollution remaining at home and the one received from other countries. ${ }^{2}$ However, when he chooses his optimal level of original research in the second stage, then transboundary pollution is partially internalized when the learning parameter is non nil $(l \neq 0)$. The higher the absorptive parameter is, the greater proportion of the negative externality is internalized.

Part of this transboundary externality is internalized when a country chooses its level of original research because such a choice, in the case of a positive learning parameter, affects the emission ratio and, therefore, the pollution of the firm of the other country, which, in turn, affects the foreign pollution received.

The first order condition of the regulator $i$ third stage is: $\frac{\partial S_{i}}{\partial q_{i}}=0$

The resolution of (3) gives:

$$
\hat{q}_{i}=\frac{a-\theta-\alpha\left(1-x_{i}^{o}-l x_{i}^{a} x_{j}^{o}\right)}{2}
$$

The symmetric expression of (4) is:

$$
\hat{q}_{i}=\frac{a-\theta-\alpha+\alpha\left(1+l x_{i}^{a}\right) x_{i}^{o}}{2}
$$

A sufficient condition for production quantities to be positive is:

$$
a-\theta>\alpha
$$

The first order conditions of regulator's $i$ second stage are: ${ }^{3}$

$$
\begin{gathered}
\frac{d S_{i}}{d x_{i}^{o}}=\frac{\partial \hat{q}_{i}}{\partial x_{i}^{o}} \frac{\partial S_{i}}{\partial q_{i}}+\frac{\partial \hat{q}_{j}}{\partial x_{i}^{o}} \frac{\partial S_{i}}{\partial q_{j}}+\frac{\partial S_{i}}{\partial x_{i}^{o}}=0 \\
\frac{d S_{i}}{d x_{i}^{a}}=\frac{\partial \hat{q}_{i}}{\partial x_{i}^{a}} \frac{\partial S_{i}}{\partial q_{i}}+\frac{\partial \hat{q}_{j}}{\partial x_{i}^{a}} \frac{\partial S_{i}}{\partial q_{j}}+\frac{\partial S_{i}}{\partial x_{i}^{a}}=0
\end{gathered}
$$

\footnotetext{
${ }^{2}$ If damages are not linear, nor separable, then transboundary pollution is partially non-internalized.

${ }^{3}$ The second order conditions are verified in the appendix when $k^{o}$ and $k^{a}$ are high enough.
} 
At the equilibrium, system (7)-(8) is simplified by using (3), and the symmetric ${ }^{4}$ solutions are given by the following equations:

$$
\begin{gathered}
2\left(\alpha+\gamma x_{i}^{a}\right) \hat{q}_{i}-\alpha \gamma l x_{i}^{a}\left[1-\left(1+l x_{i}^{a}\right) x_{i}^{o}\right]-4 k^{o} x_{i}^{o}=0 \\
\alpha l x_{i}^{o} \hat{q}_{i}-2 k^{a} x_{i}^{a}=0
\end{gathered}
$$

Using the expression of $\hat{q}_{i}$ given by (5), (9) and (10) become:

$$
\begin{gathered}
(a-\theta)\left(\alpha+\gamma l x_{i}^{a}\right)+\alpha\left[\left(1+l x_{i}^{a}\right) x_{i}^{o}-1\right]\left(\alpha+2 \gamma l x_{i}^{a}\right)-4 k^{o} x_{i}^{o}=0 \\
\alpha l x_{i}^{o}\left[a-\theta-\alpha+\alpha\left(1+l x_{i}^{a}\right) x_{i}^{o}\right]-4 k^{a} x_{i}^{a}=0
\end{gathered}
$$

The non-linear equations system (11)-(12), confirms the fact that when the learning parameter is nil $(l=0)$, transboundary pollution is completely not internalized since $\gamma$ disappears from (11)-(12). The higher $l$ is, the greater proportion of transboundary pollution is internalized.

Proposition 1. The investment in absorptive research enables non-cooperating countries to better internalize transboundary pollution. The higher is the ability of absorption, the greater is the proportion of transboundary pollution internalized.

Solving the non-linear equations system (11)-(12) gives the symmetric socially optimal R\&D levels denoted by $\hat{x}_{i}^{o}$ and $\hat{x}_{i}^{a}$. Unfortunately, we are not able to get the explicit solutions.

Proposition 2. There is a unique solution $\hat{x}_{i}^{o}>0$ and $\hat{x}_{i}^{a}>0$ that solves the non-linear equations system given by (11) and (12).

Proof: See the appendix.

Conjecture. We conjecture that: $\lim _{k^{o}, k^{a} \rightarrow+\infty} \hat{x}_{i}^{o}=\lim _{k^{o}, k^{a} \rightarrow+\infty} \hat{x}_{i}^{a}=0$.

\footnotetext{
${ }^{4}$ We look for the symmetric equilibria because the model is symmetric and computations are easier. As it will be explained in the following section, the backward resolution of the game is stopped at the second stage. Tha's why, we have the right to look for the symmetric equilibria at this second stage.
} 
This conjecture is logical because when the investment cost parameters are very high, it is socially optimal to not invest in R\&D.

\section{The non-cooperative socially optimal emission-tax and R\&D subsidies}

Given the per-unit emission-tax and the per-unit R\&D subsidies announced by the regulator in the first stage, the firm reacts by choosing its optimal research and production levels in the second and third stages, respectively. By backward induction, the firm maximizes in the third stage its net profit with respect to its production, then, in the second stage, it maximizes its net profit with respect to its R\&D levels.

The first order condition of firm $i$ third stage is: $\frac{\partial V_{i}}{\partial q_{i}}=0$

The resolution of (13) gives:

$$
q_{i}^{*}=\frac{a-\theta-t_{i}\left(1-x_{i}^{o}-l x_{i}^{a} x_{j}^{o}\right)}{4}
$$

The symmetric expression of (14) is:

$$
q_{i}^{*}=\frac{a-\theta-t_{i}\left[1-\left(1+l x_{i}^{a}\right) x_{i}^{o}\right]}{4}
$$

The first order conditions of firm $i$ second stage are: ${ }^{5}$

$$
\begin{aligned}
& \frac{d V_{i}}{d x_{i}^{o}}=\frac{\partial q_{i}^{*}}{\partial x_{i}^{o}} \frac{\partial V_{i}}{\partial q_{i}}+\frac{\partial V_{i}}{\partial x_{i}^{o}}=0 \\
& \frac{d V_{i}}{d x_{i}^{a}}=\frac{\partial q_{i}^{*}}{\partial x_{i}^{a}} \frac{\partial V_{i}}{\partial q_{i}}+\frac{\partial V_{i}}{\partial x_{i}^{a}}=0
\end{aligned}
$$

At the equilibrium, (16) and (17) are simplified by using (13), and the symmetric solutions are given by the following equations system:

$$
\begin{gathered}
t_{i} q_{i}^{*}+r_{i}^{o}-2 k^{o} x_{i}^{o}=0 \\
t_{i} l x_{i}^{o} q_{i}^{*}+r_{i}^{a}-2 k^{a} x_{i}^{a}=0
\end{gathered}
$$

\footnotetext{
${ }^{5}$ The second order conditions are verified in the appendix when $k^{o}$ and $k^{a}$ are sufficiently high.
} 
Since the emission-tax and the R\&D subsidies are set to incite firms to reach the socially optimal production and research levels which are $\hat{q}_{i}, \hat{x}_{i}^{o}$ and $\hat{x}_{i}^{a}$, then equations (15), (18) and (19) give the optimal emission-tax and R\&D subsidies:

$$
\begin{gathered}
t_{i}=\frac{a-\theta-4 \hat{q}_{i}}{1-\left(1+l \hat{x}_{i}^{a}\right) \hat{x}_{i}^{o}} \\
r_{i}^{o}=2 k^{o} \hat{x}_{i}^{o}-t_{i} \hat{q}_{i} \\
r_{i}^{a}=2 k^{a} \hat{x}_{i}^{a}-t_{i} l \hat{x}_{i}^{o} \hat{q}_{i}
\end{gathered}
$$

Proposition 3. By using the three regulatory instruments which are a per-unit emission tax, a per-unit original research subsidy and a per-unit absorptive research subsidy, noncooperative regulators can push their firms to implement the socially optimal levels of production and $R \mathcal{E} D$.

Let's notice here that the socially optimal emission-tax and R\&D subsidies are not determined directly by maximizing the social welfare function of the regulator in the first stage. They are calculated at the second stage by equalizing the socially optimal production and research levels to those optimal for the firm. In fact, the model is resolved as if it was a two-stage one.

\section{Conclusion}

We develop in this paper a non-cooperative and three-stage game played by two regulator-firm hierarchies in presence of transborder pollution and absorptive capacity.

We show that the investment in absorptive research enables non-cooperating countries to better internalize transboundary pollution. The higher the learning parameter of absorptive capacity is, the higher the proportion of transboundary pollution internalized is. Therefore, it is recommended for the international community to make the patent laws more flexible and enabling learning from the research made by others more interesting. In addition, if countries fully cooperate, then transboundary pollution is completely internalized and they reach the first best. 
Moreover, countries can implement their non-cooperative socially optimal levels of production and research by using three regulatory instruments which are the perunit emission tax, subsidy of original research and subsidy of absorptive research.

\section{Appendix}

\section{A) Second order conditions of the regulators second stage}

Consider the Hessian matrix:

$$
H_{S}=\left(\begin{array}{ll}
\frac{d^{2} S_{i}}{d x_{i}^{o 2}} & \frac{d^{2} S_{i}}{d x_{i}^{o} d x_{i}^{a}} \\
\frac{d^{2} S_{i}}{d x_{i}^{o} d x_{i}^{a}} & \frac{d^{2} S_{i}}{d x_{i}^{a 2}}
\end{array}\right)
$$

By using the first order conditions given by (7) and (8), we can determine the second derivatives constituting matrix $H_{S}$ which can be written as:

$$
H_{S}=\left(\begin{array}{cc}
f_{1}-2 k^{o} & f_{2} \\
f_{2} & f_{3}-2 k^{a}
\end{array}\right)
$$

Where $f_{i}, i=1,2,3$, are polynomial functions in $x_{i}^{o}$ and $x_{i}^{a}$ (symmetric case).

Since $\lim _{k^{o}, k^{a} \rightarrow+\infty} \hat{x}_{i}^{o}=\lim _{k^{o}, k^{a} \rightarrow+\infty} \hat{x}_{i}^{a}=0$, then $f_{i}$ take finite values when $k^{o}$ and $k^{a}$ tend to $+\infty$.

Therefore, when $k^{o}$ and $k^{a}$ are high enough:

i) $\frac{d^{2} S_{i}}{d x_{i}^{o 2}}<0$ and $\frac{d^{2} S_{i}}{d x_{i}^{a 2}}<0$,

ii) det $H_{S}=\left(f_{1}-2 k^{o}\right)\left(f_{3}-2 k^{a}\right)-f_{2}^{2}>0$.

Thus, we have a maximum when $k^{o}$ and $k^{a}$ are high enough.

\section{B) Proof of Proposition 2}

From (12), we deduce:

$$
x_{i}^{a}=\frac{\alpha l\left[a-\theta-\alpha+\alpha x_{i}^{o}\right] x_{i}^{o}}{4 k^{a}-\alpha^{2} l^{2} x_{i}^{o 2}}
$$

Expression (11) is equivalent to: 


$$
\alpha(a-\theta-\alpha)+\mathcal{H}(a-\theta-2 \alpha) x_{i}^{a}+\left(\alpha^{2}-4 k^{\grave{a}}\right) x_{i}^{o}+\alpha(\alpha+2 \gamma) l x_{i}^{o} x_{i}^{a}+2 \alpha \mathcal{1}^{2} x_{i}^{o} x_{i}^{a 2}=0
$$

Using (23) in (24), and then multiplying by $\left(4 k^{a}-\alpha^{2} l^{2} x_{i}^{o 2}\right)^{2}$, we get a polynomial function of degree 5 in $x_{i}^{o}: P\left(x_{i}^{o}\right)=0$. The constant term of $P$ is $16 \alpha(a-\theta-\alpha) k^{a 2}>0$ and the coefficient of $x_{i}^{o 5}$ is $-4 \alpha^{4} l^{4} k^{o}<0$.

We have $P(0)>0$ and $\lim _{x_{i}^{o} \rightarrow+\infty} P\left(x_{i}^{o}\right)=-\infty$, then $P\left(x_{i}^{o}\right)$ admits at least one positive root $\hat{x}_{i}^{o}>0$. Since we have shown that every critical point is a maximum when $k^{o}$ and $k^{a}$ are high enough, then we have a unique solution that solves the equations system (11)-(12). Since $\hat{x}_{i}^{o}>0$, from expression (23) and condition (6), we have $\hat{x}_{i}^{a}>0$ when $k^{o}$ and $k^{a}$ are high enough.

\section{C) Second order conditions of the firms second stage}

Consider the Hessian matrix:

$$
H_{V}=\left(\begin{array}{ll}
\frac{d^{2} V_{i}}{d x_{i}^{o 2}} & \frac{d^{2} V_{i}}{d x_{i}^{o} d x_{i}^{a}} \\
\frac{d^{2} v_{i}}{d x_{i}^{o} d x_{i}^{a}} & \frac{d^{2} V_{i}}{d x_{i}^{a 2}}
\end{array}\right)
$$

By using the first order conditions given by (16) and (17), we can determine the second derivatives constituting matrix $H_{V}$ which can be written as:

$$
H_{V}=\left(\begin{array}{cc}
g_{1}-2 k^{o} & g_{2} \\
g_{2} & g_{3}-2 k^{a}
\end{array}\right)
$$

Where $g_{i}, i=1,2,3$, are polynomial functions in $t_{i}$ and $x_{i}^{o}$ (symmetric case).

Since $\lim _{k^{o}, k^{a} \rightarrow+\infty} \hat{x}_{i}^{o}$ and $\lim _{k^{o}, k^{a} \rightarrow+\infty} t_{i}$ are finite numbers, then $g_{i}$ take finite values when $k^{o}$ and $k^{a}$ tend to $+\infty$.

Therefore, when $k^{o}$ and $k^{a}$ are sufficiently high:

i) $\frac{d^{2} V_{i}}{d x_{i}^{o 2}}<0$ and $\frac{d^{2} V_{i}}{d x_{i}^{a 2}}<0$,

ii) det $H_{V}=\left(g_{1}-2 k^{o}\right)\left(g_{3}-2 k^{a}\right)-g_{2}^{2}>0$.

Thus, we have a maximum when $k^{o}$ and $k^{a}$ are high enough. 


\section{References}

Ben Youssef, S, 2009, "Transboundary Pollution, R\&D Spillovers and International Trade", The Annals of Regional Science, 43, 235-250.

Ben Youssef, S. and G. Zaccour, 2009, "Absorptive Capacity, R\&D Spillovers, Emissions Taxes and R\&D Subsidies", HEC Montréal: Les Cahiers du GERAD No. G2009-41, MPRA Paper No. 16984.

Bjorvatn, K. and G. Schjelderup, 2002, "Tax Competition and International Public Goods", International Tax and Public Finance, 9, 111-120.

Cohen, W.M. and D.A. Levinthal, 1989, "Innovation and Learning: The Two Faces of R\&D", The Economic Journal, 99, 569-596.

D'Aspremont, C. and A. Jacquemin, 1988, "Cooperative and Noncooperative R\&D in Duopoly with Spillovers", The American Economic Review, 78, 1133-1137.

D'Aspremont, C. and A. Jacquemin, 1990, "Cooperative and Noncooperative R\&D in Duopoly with Spillovers:Erratum", The American Economic Review, 80, 641-642.

Hammerschmidt, A, 2006, "A Strategic Investment Game with Endogenous Absorptive Capacity", Vienna University of Economics \& B.A, Working Paper No. 92.

Hoel, M, 1997, "Coordination of Environmental Policy for Transboundary Environmental Problems ?", Journal of Public Economics, 66, 199-224.

Kamien, M.I. and I. Zang, 2000, "Meet me Halfway: Research Joint Ventures and Absorptive Capacity", International Journal of Industrial Organization, 18, 995-1012. Leahy, D. and J.P. Neary, 2007, "Absorptive Capacity, R\&D Spillovers, and Public Policy", International Journal of Industrial Organization, 25, 1089-1108.

Mansouri, F. and S. Ben Youssef, 2000, "Regulation and Coordination of International Environmental Externalities with Incomplete Information and Costly Public Funds", Journal of Public Economic Theory, 2, 365-388.

Milliou, C, 2009, "Endogenous Protection of R\&D Investments", Canadian Journal of Economics, 42, 184-205.

Poyago-Theotoky, J, 1999, "A Note on Endogenous Spillovers in a Non-Tournament R\&D Duopoly", Review of Industrial Organization, 15, 253-262. 
Takarada, Y, 2005, "Transboundary Pollution and the Welfare Effects of Technology Transfer", Journal of Economics, 85, 251-275.

Zagonari, F, 1998, "International Pollution Problems: Unilateral Initiatives by Environmental Groups in One Country", Journal of Environmental Economics and Management, 36, 46-69. 